\title{
Inserção e padrões de viagens de sistemas de bike-sharing em três cidades: São Paulo, Cidade do México e Nova York
}

Victor Callil

Centro Brasileiro de Análise e Planejamento, Universidade de São Paulo, Brasil

\section{Daniela Costanzo}

Centro Brasileiro de Análise e Planejamento, Universidade de São Paulo, Brasil

Recibido: 22 de agosto de 2017. Aceptado: 20 de octubre de 2017.

\section{Resumo}

O objetivo deste artigo é entender os padrões de viagens do Bike Sampa, sistema de bike-sharing de São Paulo, tendo como referência de análise outros sistemas de duas grandes cidades do mundo: o Ecobici, da Cidade do México e o City Bike, de Nova York. Os resultados permitem encontrar usos diferentes de acordo com a forma que cada sistema foi disponibilizado no espaço urbano, mas também de acordo com especificidades do funcionamento do transporte público de cada cidade.

\section{Insertion and patterns of travel of bike-sharing systems in three cities}

\begin{abstract}
The purpose of this article is to understand the travel patterns of Bike Sampa, the bike-sharing system of São Paulo. We choose systems that have been used in two big cities in world to build some comparison: Ecobici in Mexico City and City Bike in New York. The results allow us to find different uses according to the form that the system was placed in the urban space, but also according to the specificities of the operation of the public transport of each city.
\end{abstract}

\section{Introdução}

Uma forma relativamente nova de usar a bicicleta na cidade é através dos sistemas de compartilhamento de bicicletas, conhecidos como bike-sharing. Tais sistemas são compostos por estações espalhadas em diferentes pontos de uma cidade, onde

\section{Palavras-chave}

Mobilidade por bicicleta Bicicletas compartilhadas Padrões de viagens Mobilidade urbana

\section{Keywords}

Mobility by bicycle Bike-sharing Travel patterns Urban Mobility

\section{Palabras clave}

Movilidad por bicicleta Hábitos de viaje Bicicletas compartidas Patrones de viaje Movilidad urbana 
as bicicletas públicas ficam travadas, sendo possível retirar a bicicleta e utilizá-la mediante cadastro e por um período de tempo determinado, sendo que a devolução pode ser feita em qualquer outra do sistema. Sistemas de compartilhamento de bicicletas existem desde os anos 1960, mas apenas no final dos 1990 se consolidaram na forma como descrita acima (DeMaio, 2003, 2004, 2009; Shaheen et al., 2010). Eles estão presentes em cerca de 1.188 cidades (The Bike-sharing World Map, 2017) em todos os continentes do mundo.

Estes sistemas assumiram certa relevância para a mobilidade urbana, sobretudo nas grandes cidades, porque estão integrados aos demais modais do transporte público. Esta integração se dá via tarifação - a cobrança para utilização do serviço está no mesmo cartão utilizado nos outros modais - ou via localização das estações - estações próximas às paradas dos demais modais, como metrô, trem e ônibus.

Apesar de serem sistemas de utilização pública, são raros os casos em que seu financiamento vem do setor público. O modelo mais comum é via patrocínio de empresas e bancos que imprimem sua marca nas bicicletas ou trocam o investimento por locais de propaganda nas cidades (DeMaio, 2009). A utilização costuma ser tarifada em valores menores do que os dos demais modais, aumentando o valor da taxa mediante o tempo de uso. Por isso, a maior parte dos sistemas exige cartão de crédito para utilização e controle das bicicletas.

A implantação de um sistema de compartilhamento de bicicletas engloba elementos caros como as estações, as bicicletas e as fontes de energia utilizadas, serviços de alta complexidade de TI e logística, o gerenciamento do sistema e de aplicativos para usuários, a reposição da frota cotidianamente e a manutenção. Por isso, a localização das estações e as estratégias de balanceamento da quantidade de bicicletas em cada estação são pontos fundamentais para o bom funcionamento do sistema, ou seja, para que sempre haja bicicletas e vagas vazias nas estações, possibilitando a retirada e a devolução em todas as estações e aumentando a confiabilidade do sistema.

Do ponto de vista da utilização dos sistemas de bike-sharing, pouco se sabe sobre seus padrões de viagem e sua inserção nas cidades. Há apenas um estudo sobre os horários e locais comuns de uso do sistema Bicing de Barcelona (Froehlich, Neumann \& Oliver, 2008). Assim sendo, este artigo dedica-se a entender os padrões de viagens e a inserção do bike-sharing nas respectivas cidades de três sistemas diferentes: Bike Sampa (São Paulo), CitiBike (Nova York) e Ecobici (Cidade do México). A escolha das cidades se baseou primeiramente no tamanho delas e na complexidade da mobilidade urbana nestes locais, em segundo lugar, foram levantadas cidades que têm o sistema consolidado (em operação há pelo menos dois anos) e em terceiro, foram consideradas as trajetórias semelhantes das políticas públicas para mobilidade por bicicleta.

O objetivo deste artigo é entender os padrões de utilização de bike-sharing nestas três cidades e como os sistemas se inserem e se relacionam com o meio urbano, considerando as ciclovias e os demais modais de transporte. Tal comparação visa compreender melhor o Bike Sampa, testando suas variáveis em paralelo com os outros dois sistemas, possibilitando avaliar e consolidar os parâmetros de análise que serão utilizados aqui.

Desta forma, o artigo se divide em 3 partes, além desta introdução e da conclusão. $\mathrm{Na}$ primeira parte apresentamos as características descritivas dos sistemas analisados. Na segunda, explicamos as escolhas metodológicas e categorias de análise utilizadas. Por fim, apresentamos os cruzamentos dos dados e os principais achados e hipóteses sobre os sistemas. 


\section{Sistemas analisados}

Os três sistemas analisados aqui funcionam há pelo menos 3 anos, possuem um número alto de estações (ver Quadro 1), operam por pelo menos 16 horas por dia e têm entre 30 minutos e 1 hora de utilização gratuita para os usuários cadastrados. O cadastro e a compra dos passes são cobrados de formas diferentes nas três cidades, enquanto em São Paulo é gratuito, em Nova York e na Cidade do México há cobrança de passes diários, mensais ou anuais. A forma de retirar a bicicleta também varia nos três lugares, sendo somente por senha digitada na estação em Nova York e variando entre aplicativo de celular, cartão do transporte e atendimento telefônico em São Paulo e na Cidade do México. Nos três casos, há financiamento privado, sendo impressa na bicicleta a marca do patrocinador em São Paulo e em Nova York. No caso mexicano, o patrocinador explora espaços de anúncio na cidade.

Quadro 1. Os três sistemas. Fonte: Elaboração própria a partir dos dados dos sistemas. As informações foram colhidas nas seguintes datas: Bike Sampa em Outubro de 2015; Citi Bike em Abril de 2015; Ecobici em Maio de 2015.

\begin{tabular}{|c|c|c|c|c|c|c|c|c|}
\hline Cidade & Sistema & $\begin{array}{l}\text { Início da } \\
\text { operação }\end{array}$ & Estações & Horário & Tarifa & $\begin{array}{c}\text { Tempo máximo } \\
\text { de utilização sem } \\
\text { multa }\end{array}$ & Forma de retirada & Financiamento \\
\hline São Paulo & $\begin{array}{l}\text { Bike } \\
\text { Sampa }\end{array}$ & 2012 & 252 & $6 h-22 h$ & Gratuito & 1 hora & $\begin{array}{l}\text { Aplicativo de celular, } \\
\text { Autoatendimento } \\
\text { telefônico, Cartão do } \\
\text { transporte }\end{array}$ & $\begin{array}{c}\text { Patrocínio do Banco } \\
\text { Itaú }\end{array}$ \\
\hline Nova York & Citi Bike & 2013 & 303 & 24 horas & $\begin{array}{l}\text { US\$10 (passe diário) } \\
\text { US\$15o (passe anual) }\end{array}$ & $\begin{array}{l}30 \text { minutos (passe } \\
\text { diário) } \\
45 \text { minutos (passe } \\
\text { anual) }\end{array}$ & Senha na estação & $\begin{array}{l}\text { Patrocínio do } \\
\text { Citibank }\end{array}$ \\
\hline $\begin{array}{l}\text { Cidade do } \\
\text { México }\end{array}$ & Ecobici & 2010 & 425 & $6 h-24 h$ & $\begin{array}{l}\text { MXN\$90 (passe } \\
\text { mensal) MXN\$400 } \\
\text { (passe anual) }\end{array}$ & 45 minutos & $\begin{array}{l}\text { Cartão do transporte, } \\
\text { Senha na estação }\end{array}$ & $\begin{array}{l}\text { Patrocínio da } \\
\text { agência Clear } \\
\text { Channel }\end{array}$ \\
\hline
\end{tabular}

\section{Metodologia}

Para melhor analisar os sistemas, foram coletados os dados automáticos de viagens gerados pelo sistema para cada retirada de bicicleta. A unidade de análise escolhida foi a de um mês, com o recorte de 28 dias para equilibrar a proporção de dias úteis e finais de semana, sendo 20 dias úteis (4 unidades de dia para cada dia da semana - segunda, terça, quarta, quinta e sexta) e 8 dias de finais de semana (4 sábados e 4 domingos). Foram eliminadas dos bancos as viagens com menos de 2 minutos ou com mais de 1 hora e meia, pois estas eram residuais e influenciavam nos tempos médios. Além disso, as viagens com menos de 2 minutos podem ser consideradas retirada e devolução de bicicletas com problema.

Entre os dias analisados foram excluídos aqueles com chuva e feriados. Optou-se por montar a amostra com meses diferentes entre os sistemas para não correr o risco de analisar um sistema em uma estação do ano e outro sistema em um momento mais frio ou mais quente. A despeito dos ruídos que invariavelmente entraram na análise e dos quais não temos controle compostos por fatores específicos de uma municipalidade (grandes obras, manifestações populares, grandes eventos, etc.), os bancos são comparáveis. Assim, o Bike Sampa teve sua extração de dados entre o final de Setembro e o começo de Outubro, o Citi Bike em Abril e o Ecobici em maio. Todos do ano de 2015 (ver Quadro 2). 
Inserção e padrões de viagens de sistemas de bike-sharing em três cidades... [7-16]

Quadro 2. Datas da extração dos bancos de dados. Fonte: elaboração própria.

\begin{tabular}{|l|c|c|}
\hline Cidade & Sistema & Período de coleta de dados \\
\hline São Paulo & Bike Sampa & Set/15 e out $/ 15$ \\
\hline Nova York & Citi Bike & Abr/15 \\
\hline Cidade do México & Ecobici & Mai/15 \\
\hline
\end{tabular}

Para analisar as viagens, foram construídas variáveis baseadas em tipos de dias (dias úteis e finais de semana), tempo de viagem e em retiradas com devolução na mesma estação ou em estações diferentes. A separação entre dias úteis e finais de semana se mostrou relevante porque as viagens possuem características diferentes nestes dias, com viagens mais longas e devolução na mesma estação em finais de semana. Este tipo de viagem pode ser associado a passeio ou esporte, já que o usuário utiliza a bicicleta para voltar ao mesmo ponto de onde saiu. No caso das viagens com devolução em estações diferentes, pressupõe-se que há deslocamento, já que sai de um lugar e chegar a outro. O tempo de viagem, por sua vez, permite identificar viagens curtas para acessar um lugar próximo, muitas vezes nas imediações de outros modais, e viagens para acessar lugares mais distantes ou para lazer/atividades físicas, estas últimas em geral tem maior duração.

A análise conjunta de tempo de viagem e devolução na mesma estação permite melhor caracterização das viagens para deslocamento ou para atividade física. Para isto, foram criados dois indicadores: Indicador de Viagens para Deslocamento (IVD) e Indicador de Viagens para Lazer (IVL). O IVD é composto de viagens com retirada e devolução em estações diferentes e por viagens com até 30 minutos. O IVL tem viagens com retirada e devolução na mesma estação e com mais de 30 minutos e viagens com mais de uma hora. A criação desses indicadores permite consolidar os dados de uso sobre os sistemas. Ou seja, a agregação de algumas variáveis que declaradamente possuem determinadas qualidades ajuda a caracterizar os sistemas analisados.

Convém explicar que não será trabalhada a motivação das viagens, pois esta variável depende de pesquisa direta com os ciclistas. Logo, ainda que possamos, em função das características observadas, supor que a maior parte das viagens para deslocamento tenha como finalidade trabalho ou estudo, não é possível definir um qualificador desse tipo. Assim, o IVD explicita viagens (seja para compras, seja para trabalhar, seja para ir para a escola/faculdade, etc.) que provavelmente seriam feitas com outro modal caso não fossem feitas com a bicicleta compartilhada. Por outro lado, o IVL tem como objetivo captar as viagens onde o ciclista não realizou deslocamento de um ponto $\mathrm{A}$ para um ponto $\mathrm{B}$, mas sim utilizou a bicicleta para atividades físicas ou um passeio sem finalidade de se deslocar pelo território urbano.

\section{Resultados e análise}

Com base na literatura e nos dados analisados, estabelecemos 2 eixos de análise. O primeiro diz respeito aos tipos de usos do sistema. O segundo trata da inserção dos sistemas nas cidades, suas densidades e as distâncias entre uma estação e outra.

\section{Tipos de usos dos sistemas e compartilhamento das bicicletas}

A bicicleta compartilhada, como dissemos anteriormente, em geral é um recurso para aumentar e melhorar as possibilidades de deslocamento em uma cidade. Ainda que o uso para transporte também ocorra aos finais de semana, observar a proporção de viagens realizadas nos dias úteis é uma boa medida para averiguar se aquele sistema tem um apelo maior ou menor como ferramenta para o deslocamento na cidade. 

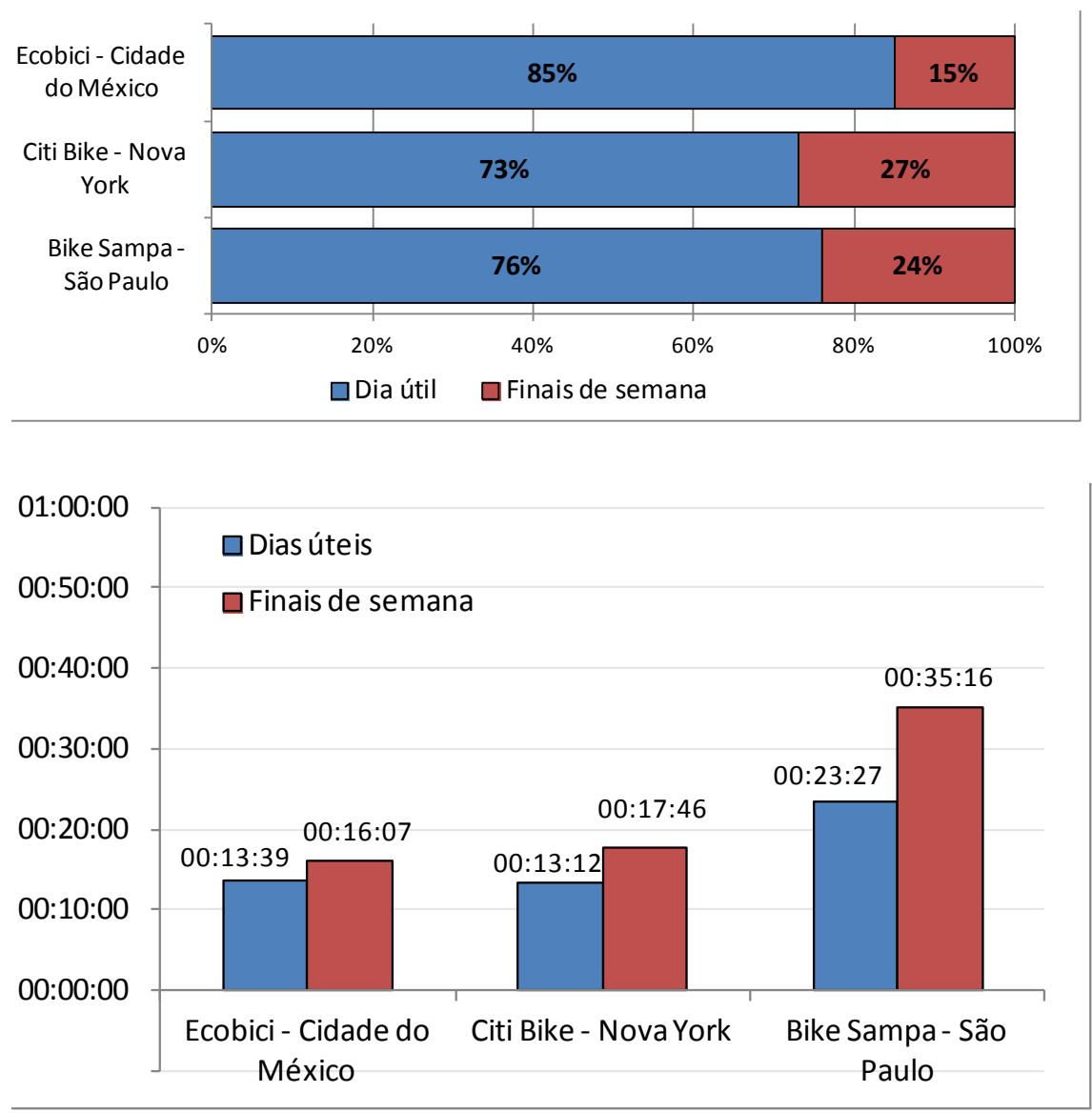

A Figura 1 indica que a maior parte das viagens realizadas em todos os sistemas possui concentração em dias úteis. Um sistema com uma divisão igualitária das viagens entre os dias da semana apresentaria cerca de $71 \%$ das viagens em dias úteis e o restante em finais de semana. No entanto, a concentração do uso em dias úteis do Ecobici é maior que dos outros dois sistemas. Este dado pode ser melhor entendido se analisado em conjunto com outros dois indicadores: o tempo médio das viagens e o volume de retiradas com devolução na mesma estação.

O tempo médio de viagem no Bike Sampa (Figura 2) supera o dos outros dois sistemas. A distribuição das viagens no boxplot (Figura 3 ) nos mostra que o $3^{\circ}$ quartil de tempo de viagem do sistema paulistano equivale ao $4^{\circ}$ quartil dos outros dois sistemas. $\mathrm{Ou}$ seja, a média de tempo maior não é afetada pela presença de algumas viagens de maior duração, já que os valores atípicos - outliers - foram retirados, mas trata-se de uma característica de uso de fato diferente.

Essa disparidade na duração das viagens pode ter como um dos fatores explicativos a distância média percorrida. Foi verificado que o trajeto tem, em média, 2.441 metros no Bike Sampa, enquanto que no sistema mexicano esse valor é de 1.648 metros e do nova-iorquino 1.710. Assim, o tempo médio mais alto do sistema paulistano pode ser explicado também pelas distâncias percorridas, que são 68\% maior que o Ecobici e $70 \%$ maior que o Citi Bike.

Além do comprimento do percurso, outras variáveis que podem influenciar no tempo médio é a distância entre as estações e o volume de retiradas com devolução na mesma estação que, no Bike Sampa, é maior.
Figura 1. Distribuição das viagens por tipo de dia por sistema. Fonte: elaboração própria.

Figura 2. Tempo médio de viagem por tipo de dia. Fonte: elaboração própria. 

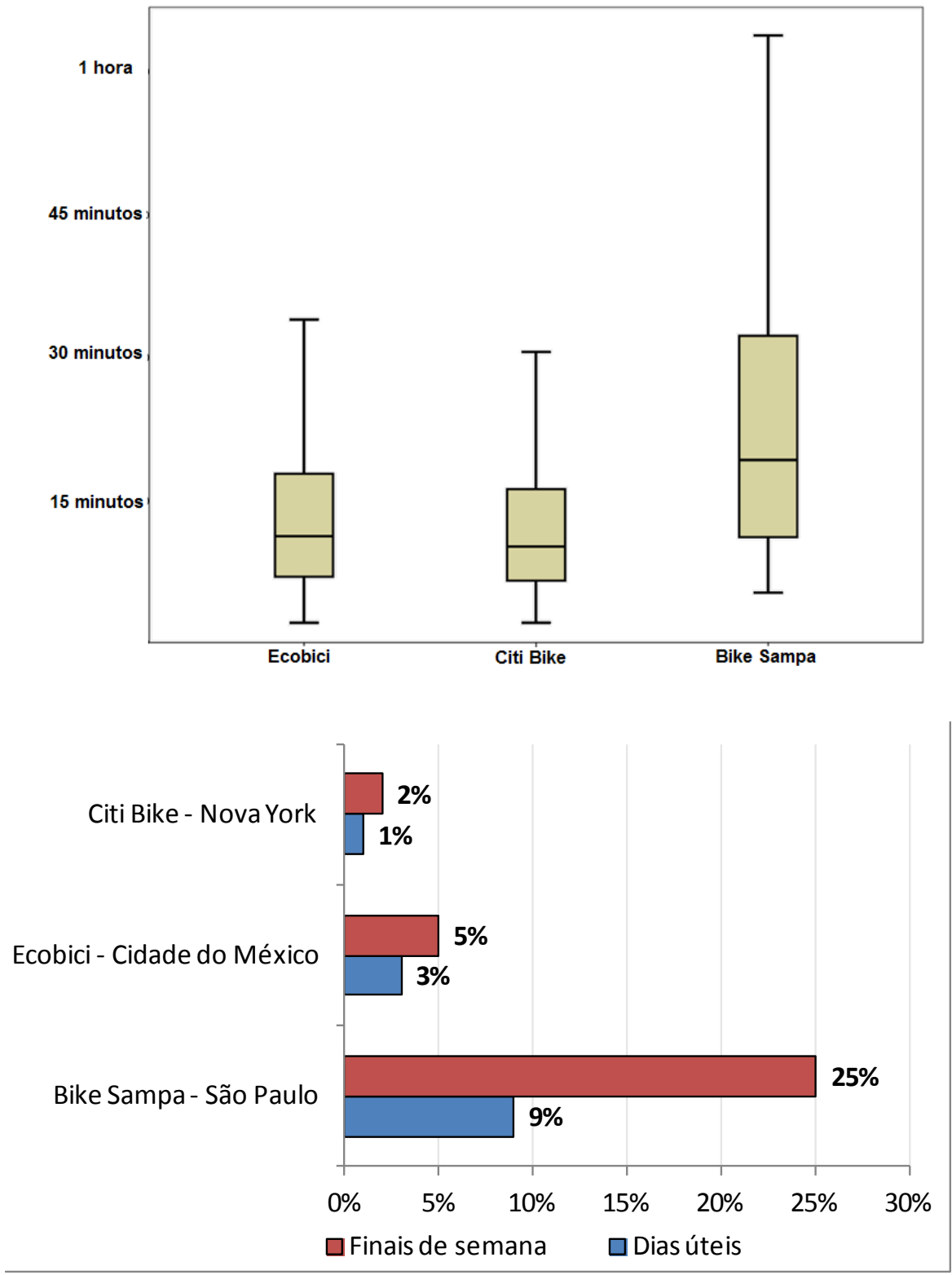

Enquanto nos sistemas internacionais colocados em análise 1\% ou 3\% de viagens em dias úteis tiveram origem e destino no mesmo ponto, esse percentual em São Paulo é de 9\%. Vale destacar que usar a bicicleta compartilhada para lazer não é, à primeira vista, algo negativo. No entanto, se analisarmos da perspectiva tanto da eficácia quanto da eficiência do bike-sharing, veremos que um volume muito alto de viagens deste tipo pode ser prejudicial para o seu funcionamento. Primeiramente, porque as pessoas que estão passeando ou praticando atividades físicas costumam ficar mais tempo com a bicicleta, o que faz com que durante todo esse período ela não se preste ao motivo pelo qual existe - ser compartilhada. A tabela abaixo (Quadro 3) nos mostra, justamente, que são as viagens com maior tempo de duração que possuem maior proporção de retiradas com devolução na mesma estação, indicando que viagens com tais características têm maior possibilidade de representarem usos para passeio ou atividade física.
Figura 3. Boxplot para tempo de viagem em dias úteis*. Fonte: elaboração própria. *Outliers excluídos do gráfico para melhor visualização.
Figura 4. Percentual de retiradas com devolução na mesma estação por tipo de dia. Fonte: elaboração própria. 
Quadro 3. Duração da viagem por local de retirada e devolução do Bike Sampa em dias úteis. Fonte: elaboração própria.

\begin{tabular}{|l|c|c|c|}
\hline $\begin{array}{l}\text { Faixa de duração } \\
\text { (Bike Sampa) }\end{array}$ & Estações diferentes & Mesma estação & Total Geral \\
\hline Até 15 minutos & $97 \%$ & $3 \%$ & $100 \%$ \\
\hline De 15 a 30 minutos & $95 \%$ & $5 \%$ & $100 \%$ \\
\hline De 30 a 45 minutos & $85 \%$ & $15 \%$ & $100 \%$ \\
\hline De 45 minutos a 1 hora & $71 \%$ & $29 \%$ & $100 \%$ \\
\hline Mais de 1 hora & $69 \%$ & $31 \%$ & $100 \%$ \\
\hline Total Geral & $91 \%$ & $9 \%$ & $100 \%$ \\
\hline
\end{tabular}

Por retornar ao mesmo ponto de origem, as viagens com essa característica também acabam fazendo com que a bicicleta circule pouco pela cidade e esteja menos disponível em regiões onde ela poderia ser mais demandada. Além de pressupor que não houve deslocamento, o compartilhamento da bicicleta fica comprometido, afinal, é como se aquela bicicleta tivesse ficado indisponível durante um grande período de tempo e depois voltasse a ficar disponível no mesmo lugar, só que esse tempo indisponível gerou nela os impactos do uso, o gasto do material.

Por fim, a despeito de um maior volume de retiradas com devolução na mesma estação no caso brasileiro, é possível afirmar que os três sistemas apresentam um uso fortemente voltado para o deslocamento em dias úteis. Entre eles, o Bike Sampa é o único que contém, com alguma representatividade, uso para lazer em dias úteis. A Figura 5 mostra o indicador de viagens para deslocamento (IVD) e o indicador de viagens para lazer (IVL) dos três sistemas.

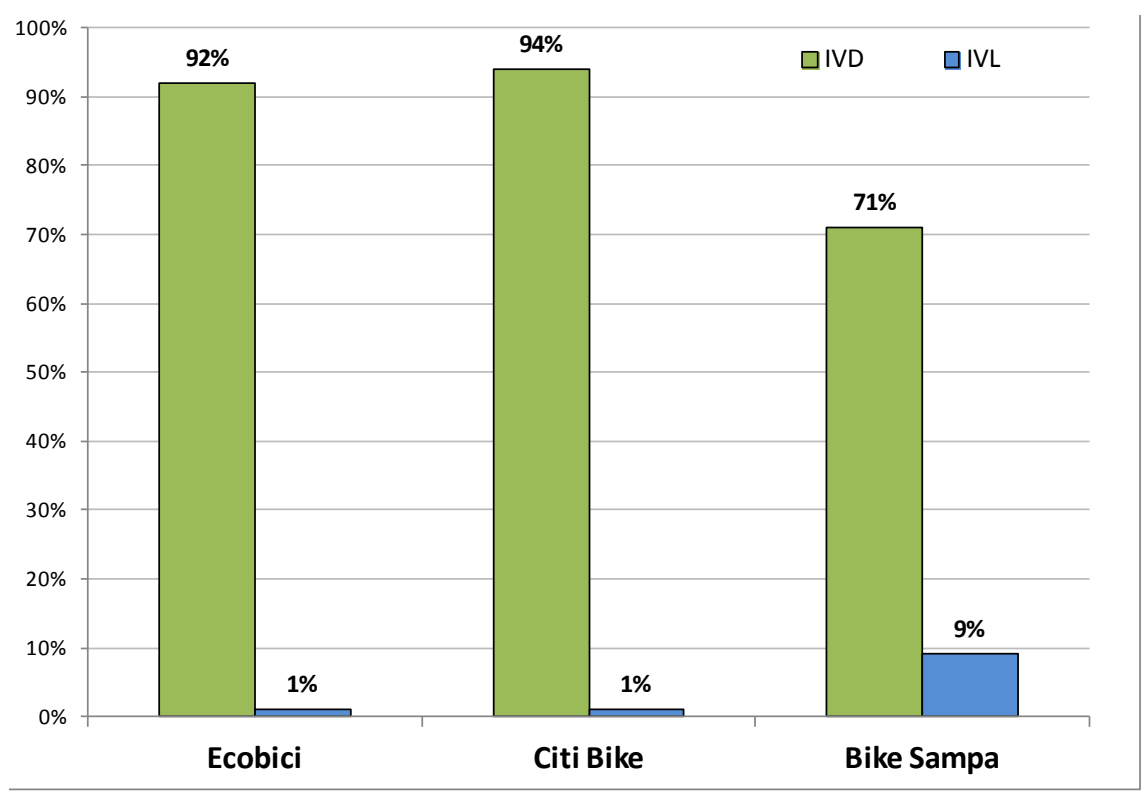

Figura 5. IVD e IVL em dias úteis. Fonte: elaboração própria.

Mesmo com um IVD menor do que os outros dois sistemas, o Bike Sampa apresenta $71 \%$ das suas viagens em dias úteis com características claras de deslocamento. Um elemento que influencia bastante o IVL mais alto que os outros dois sistemas são, mais uma vez, as retiradas com devolução na mesma estação que, como vimos anteriormente, parecem mais recorrentes no sistema paulistano. 


\section{Inserção dos sistemas nas cidades - quantidade e localização das estações}

Os três sistemas analisados possuem características distintas em relação à quantidade e localização das estações na cidade. A área atendida pelos sistemas é diferente entre eles e a distância média entre as estações é bem maior em São Paulo do que nas outras duas cidades. Por consequência, a densidade de estações por $\mathrm{km}^{2}$ também é maior nos casos internacionais aqui analisados.

Em 2014, o Instituto de Política de Transporte e Desenvolvimento (ITDP) publicou um "Guia de planejamento de sistemas de bicicletas compartilhadas". Dentre diversos temas relativos à implantação de um sistema de bike-sharing estão: modelos de negócios para gerir os sistemas, modelos de financiamento e custos de implantação. $\mathrm{O}$ material sugere também, com base em 3 indicadores ${ }^{1}$ uma densidade média de uma estação a cada 300 metros. É preferível que as estações estejam sempre adjacentes aos terminais de transportes públicos e, sempre que possível, devem estar localizadas ao longo das ciclovias da cidade.

O Quadro 4 mostra que o Bike Sampa é o sistema com o menor número de estações por $\mathrm{km}^{2}$, assim, é plausível que a distância média pedalada por seus usuários seja maior, como exposto na sessão anterior. O perímetro atendido é 3 vezes maior que o perímetro do Ecobici, sendo o volume de estações, entretanto, quase a metade do sistema mexicano. A densidade ajuda a entender também porque o IVL de São Paulo é maior do que os dos outros sistemas, já que as viagens tendem a ser mais demoradas, e o menor número de estações próximas incentiva a devolução na mesma estação. Tendo em vista uma quantidade limitada de recursos para investir na implantação de um bike-sharing, a questão sempre se coloca: é melhor atender a uma região menor e ter maior densidade de estações ou uma região maior e aumentar a distância média ente uma estação e outra?
1. A) Coeficiente de Densidade de Estações: número médio de estações em determinada área. B) Coeficiente de bicicletas/população: média de bicicletas por pessoa na área de cobertura. C) Coeficiente de vagas/bicicleta: número médio de vagas por bicicleta.

Quadro 4. Características dos sistemas. Fonte: elaboração própria.

\begin{tabular}{|l|c|c|c|c|c|}
\hline Sistema & $\mathbf{N}^{\circ}$ de estações & Área do sistema & Estações por $\mathrm{Km}^{2}$ & $\begin{array}{c}\text { Distância média } \\
\text { entre as estações }\end{array}$ & $\begin{array}{c}\text { Distância média } \\
\text { pedalada em dias } \\
\text { úteis }\end{array}$ \\
\hline Bike Sampa & 252 & $125 \mathrm{~km}^{2}$ & 2 & 446 metros & 2.218 metros \\
\hline Citi Bike & 319 & $50 \mathrm{~km}^{2}$ & 6 & 256 metros & 1.710 metros \\
\hline Ecobici & 425 & $37 \mathrm{~km}^{2}$ & 11 & 190 metros & 1.1648 metros \\
\hline
\end{tabular}

Se a primeira opção garante um melhor controle sobre o sistema, facilitando a operação cotidiana e permitindo uma penetrabilidade mais intensa nos bairros atendidos, a segunda opção disponibiliza o sistema para locais onde, muitas vezes, nunca houve nenhuma política cicloviária. A decisão sobre onde e como devem ser instaladas as estações obedece a uma série de critérios técnicos e políticos, que podem ter pesos desproporcionais, e que serão determinantes para o tipo de funcionamento que o sistema terá.

Vale ressaltar que os sistemas de compartilhamento de bicicleta tendem a intensificar o seu uso em regiões próximas a estações de metrô e de transportes de alta capacidade. Esse exemplo pode ser visto, no Bike Sampa, nas estações de metrô Faria Lima (que, por conta da grande demanda, foi necessário duplicar a estação ali existente), terminal Pinheiros, metrô Fradique Coutinho e a estação Berrini da CPTM. É importante destacar que em todos os casos a estação do bike-sharing fica exatamente em frente ou dentro do terminal. Enquanto em São Paulo pudemos verificar $8 \%$ das estações do Bike Sampa a até 200 metros de um modal de alta capacidade (trem ou metrô), em Nova York esse percentual é de 39\% e na Cidade do México de 12\%. 
Se tanto em Nova York como na Cidade do México o bike-sharing está extremamente afinado com a estrutura cicloviária da cidade (López, 2013; Gordon-Koven e Levenson, 2014), em São Paulo a implantação das ciclovias não ocorreu ao mesmo tempo que a implementação do sistema de compartilhamento de bicicletas. O mapeamento e a implantação das estações do Bike Sampa começaram no ano de 2012, a implantação das ciclovias de modo massivo teve início em 2014, quando boa parte das estações existentes do Bike Sampa já estavam instaladas. O lado positivo é que as estações do sistema paulistano são facilmente removíveis e reinstaladas em outro local. Por utilizarem placas solares como fonte de energia não precisam utilizar fiação subterrânea e nem serem concretadas no chão, de modo que sua versatilidade permite um remanejamento bastante eficiente. O lado negativo é que elas precisam ser alocadas sempre em lugares onde haja incidência da luz solar (Shu et al., 2010 e em Angeloudis et al., 2014).

\section{Considerações finais}

Como é possível notar nos dados apresentados, os sistemas, quando analisados com mais profundidade, têm perfis de uso diferentes - sobretudo São Paulo. Nesta cidade, as viagens tendem a ser mais demoradas, a proporção de uso em finais de semana é maior e as retiradas com devolução na mesma estação também. Isso possivelmente ocorre em função da localização de algumas estações, que possuem alto volume de viagens, próximas a locais onde o uso recreativo das bicicletas tende a ser maior (parques, praças, etc.), a menor densidade do sistema também parece influenciar, pois aumenta a distância entre as estações, solicitando ao usuário um maior tempo de deslocamento.

Assim, apesar de o Bike Sampa possuir uma cobertura mais ampla do território urbano, parece apresentar uma articulação menos consolidada com o sistema de transportes estrutural da cidade se comparado com os outros dois casos aqui analisados. Além disso, a distância maior observada entre as estações e a falta de aderência mais intensa com a infraestrutura cicloviária sugere que o sistema paulistano tem sido subutilizado em algumas regiões. 


\section{Q Bibliografia}

» Angeloudis, P., Hu, J., Bell, M. (2014). A strategic repositioning algorithm for bicycle-sharing schemes. Transportmetrica A: Transport Science, 10 (8), 759-774.

»Demaio, P. (2003). Smart bikes: Public transportation for the 21st century. Transportation Quarterly 57(1).

"Demaio, P. (2004). Will Smart Bikes Succeed as Public Transportation in the United States? Journal of Public Transportation, 7 (2).

»Demaio, P. (2009). Bike-sharing: History, Impacts, Models of Provision, and Future. Journal Of Public Transportation 12 (4), 41-56.

»Froehlich, J., Neumann, J., OLIVER, N. (2008). Measuring the Pulse of the City through Shared Bicycle Programs. Urban Sense 8, 16-20.

» Gordon-Koven, L.; Levenson, N. (2014). Citi Bike takes New York. Rudin Center for Transportation Management and Policy NYU Robert F. Wagner Graduate School of Public Service. Nova York.

"López, R. (2013). El sistema de bicicletas públicas “Ecobici”: del cambio modal al cambio social. Espacialidades 03 (2).

»Shu, J., Cgou M., Lui, Q., Teo, C. P., Wang, I-L. (2010). Bicycle-sharing system: deployment, utilization and the value of re-distribution. Presented at the INFORMS Annual Meeting, Charlotte.

»The Bike-Sharing World Map (2017). Disponível em: http://bike-sharing. blogspot.com.br/ Acesso em 19 de abril de 2017.

» Shaheen, S., Guzman, S., Zhang, H. (2010). Bikesharing in Europe, the Americas, an Asia: Past, Present, and Future. Washington D.C.: Transportation Research Board Annual Meeting.

\section{Victor Callil / victor.callil@cebrap.org.br}

Mestre em Sociologia pela Universidade de São Paulo (USP), pesquisador do Centro Brasileiro de Análise e Planejamento (CEBRAP). Desenvolve pesquisa sobre mobilidade urbana por bicicletas e, desde 2011, vem atuando em trabalhos em parceria tanto com o poder público como com a iniciativa privada.

\section{Daniela Costanzo / danicosper@gmail.com}

Mestra em Ciência Política pela Universidade de São Paulo (USP), pesquisadora do Centro Brasileiro de Análise e Planejamento (CEBRAP), Tem experiência na área de Ciência Política, com ênfase em Políticas Públicas e nas relações entre Estado e iniciativa privada. 